\title{
O SENSO COMUM E A FILOSOFIA ${ }^{1}$
}

\author{
Common sense and philosophy \\ El senso común y filosofía
}

Regina Schöpke ${ }^{2}$

Universidade Estadual do Rio de Janeiro, Rio de Janeiro, RJ, Brasil.

\section{Resumo}

Ainda que pouco conhecido e estudado em nossa época, o filósofo neokantiano russo, de origem greco-alemã, Afrikan Spir, produziu uma obra original que teve repercussões importantes em seu tempo. Nascido um pouco antes de Nietzsche, em 1837, Spir será citado por ele, sobretudo, no que se refere às questões que envolvem o caráter transcendental do conhecimento. Afinal, como Kant, Spir defende que o mundo nos aparece mediado por nossa sensibilidade; mediado e organizado pelas estruturas " $a$ priori" do conhecimento, ou seja, do mundo recebemos apenas impressões sensoriais,

\footnotetext{
O artigo "Le sens commun et la philosophie", escrito pelo filósofo russo neo-kantiano do século XIX, Afrikan Spir, foi publicado, originalmente, na Revue de Métaphysique et de Morale, tome III, 1895, p. 435-441. (N. T.)

2 Regina Schöpke é filósofa, historiadora e Professora Adjunta do Departamento de Filosofia e do PPGFIL da Universidade Estadual do Rio de Janeiro (UERJ). Pós-Doutora e Doutora em Filosofia, é autora dos livros: Por uma filosofia da diferença: Gilles Deleuze, o pensador nômade (Contraponto Editora), Matéria em movimento: a ilusão do tempo e o eterno retorno (Martins Fontes) e Dicionário Filosófico (Martins Fontes). É tradutora de diversas obras de filosofia e ciências humanas e sociais e, durante anos, foi resenhista de livros em jornais de grande circulação. http://orcid.org/0000-0001-7246-6633. E-mail: rschoepke@uol.com.br
} 
qualidades sensíveis, cabendo ao sujeito cognoscente ordená-las a partir de suas intuições. No entanto, na intitulada filosofia crítica de Spir, o único e o verdadeiro, à priori, é o "princípio de identidade", que seria o responsável pela síntese do conhecimento, seja de nós mesmos, seja dos objetos do mundo. Em poucas palavras, segundo Spir, e contestando o senso comum e o próprio objetivismo científico, não existe nada que seja estável e absoluto fora de nós. Todo o absoluto diz respeito ao pensamento. Mesmo o "eu" nada mais é do que uma síntese operada pela consciência.

Palavras-chave: Afrikan Spir. Conhecimento. Absoluto. Princípio de identidade. Consciência.

\begin{abstract}
Although little known and studied in our time, the Russian neo-Kantian philosopher, of Greco-German origin, Afrikan Spir, produced an original work that had important repercussions in its time. Born shortly before Nietzsche in 1837 , Spir will be quoted by him, above all, as regards the questions that involve the transcendental character of knowledge. After all, like Kant, Spir argues that the world appears to us mediated by our sensitivity; mediated and organized by the a priori structures of knowledge, that is, from the world we receive only sensory impressions, sensitive qualities, and it is up to the cognoscenti subject to order them from their intuitions. However, in Spir's critical philosophy, the only true a priori is the principle of identity, which would be responsible for the synthesis of knowledge, either of ourselves or of the objects of the world. In short words, according to Spir, and contesting common sense and scientific objectivism itself, there is nothing that is stable and absolute outside of us. All absolute refers to thought. Even the $l$ is nothing more than a synthesis operated by consciousness.
\end{abstract}

Keywords: Afrikan Spir. Knowledge. Absolute. Principle of identity. Consciousness.

\title{
Resumen
}

Aunque poco conocido y estudiado en nuestro tiempo, el filósofo neokantiano ruso, de origen greco-alemán, Afrikan Spir, produjo una obra original que tuvo repercusiones importantes en su tiempo. Nació un poco antes de Nietzsche, en 1837, Spir será mencionado por él, especialmente con respecto a cuestiones relacionadas con el carácter trascendental del conocimiento. Después de todo, de la misma forma como Kant, Spir argumenta que el mundo aparece mediado por nuestra sensibilidad; mediado y organizado por las estructuras "a priori" del conocimiento, es decir, del mundo recibimos solamente impresiones sensoriales, cualidades sensibles, debiendo el sujeto cognoscente ordenar 
el conocimiento a partir de sus intuiciones. Sin embargo, en la titulada filosofía crítica de Spir, el único y verdadero a priori es el principio de identidad, que sería responsable de la síntesis del conocimiento, sea de nosotros mismos, sea de los objetos del mundo. En Resumen, segundo Spir, y desafiando el sentido común y el objetivismo científico, no hay nada que sea estable y absoluto fuera de nosotros. Todo el absoluto concierne al pensamiento. Incluso el yo nada más es que una síntesis operada por la conciencia.

Palabras clave: Afrikan Spir. Conociminento. Absoluto. Principio de identidade. Conciencia.

Seria tempo de regular o debate entre o senso comum e a filosofia. $O$ senso comum toma as coisas como elas se apresentam; ele toma, portanto, a aparência pela realidade, ao passo que a filosofia desvela a aparência e constata os fatos tais como eles realmente são. Ora, na realidade, o enunciado dos fatos tais como eles são apresenta, ele próprio, aparentes contradições lógicas, e o senso comum não deixa, por conseguinte, de taxar a filosofia de absurda. Para colocar as coisas às claras, é necessário estabelecer estes três pontos:

a) Mostrar que os fatos e os objetos deste mundo não podem conter contradições lógicas, ainda que apresentem a aparência disso;

b) -Mostrar de onde provém, nos objetos da experiência, esta aparência de contradições lógicas, e o que ela significa;

c) Mostrar que o senso comum se move realmente, sem desconfiar disso, em algumas contradições lógicas. Uma contradição lógica é a incompatibilidade absoluta entre dois termos que, no entanto, se reúnem, como a afirmação e a negação da mesma coisa. Ora, o mundo físico não contém nada de absoluto fora de nosso pensamento; somente o nosso pensamento é capaz de concepções absolutas; portanto, é apenas em nosso pensamento, e não nos objetos do pensamento, que podem ser encontradas as contradições absolutas. A realidade, pelo próprio fato de que está submetida a algumas condições, está fora do domínio próprio da lei lógica fundamental, e não pode, por conseguinte, 
ser diretamente oposta a ela, mesmo quando dá a impressão de Ihe ser oposta: ela é "ilógica”, mas não "antilógica”.

Porém, as coisas deste mundo, se não estão em conformidade com a regra de nosso pensamento, estão, no entanto, organizadas de maneira a parecer em conformidade com essa regra. Assim, haveria um desacordo lógico entre a natureza verdadeira das coisas e o seu papel na aparência; e como o nosso espírito está habituado a perceber as coisas não tais como elas realmente são, mas tais como elas se apresentam na aparência natural, o enunciado de sua natureza real parece, para uma visão superficial, implicar algumas contradições lógicas. Mas, de fato, incorre-se, ao contrário, em semelhantes contradições quando se toma a aparência pela realidade e quando se atribui aos objetos da experiência um caráter absoluto. Vamos demonstrar isso tanto com relação ao nosso eu quanto com relação ao mundo exterior.

Eis aqui, primeiramente, algumas observações gerais.

É preciso distinguir um objeto real, tendo uma natureza que lhe é própria e, por conseguinte, absoluta (uma substância), de um fenômeno que é, ele próprio, um produto de causas: a unidade de um é absoluta; a unidade do outro só pode ser relativa, condicional. Do mesmo modo, é preciso distinguir a permanência absoluta de um ser real, que está em si preservado da mudança, que existe fora do tempo (a invariabilidade de uma substância), da permanência de um fenômeno que é ela mesma produzida por algumas causas e consiste em um renascimento perpétuo no tempo. Tudo aquilo que tem um começo no tempo e, por conseguinte, tudo aquilo que é produzido por causas, não é uma substância, mas um fenômeno ou um acontecimento, e não persiste senão se reproduzindo novamente sem cessar.

Retomemos agora o nosso tema.

Parece, à primeira vista, totalmente absurdo dizer que nós mesmos não somos objetos reais, mas simples fenômenos, simples efeitos de certas causas, que nossa personalidade ou nosso eu não é uma substância, uma unidade indivisível e totalmente a mesma em diferentes tempos - ou seja, 
existindo, por sua essência, fora do tempo. Negar a si mesmo não seria o cúmulo do absurdo? Como acreditar - dirão - que existam pensamentos sem um sujeito indivisível e permanente que pensa? Que nós possamos sentir a alegria e a dor sem que exista em nós uma substância, nem alguma coisa irredutível e real que sofra e se regozije? No entanto, esses são fatos. Eles são, na verdade, incompreensíveis e inexplicáveis, mas não contêm contradição lógica, pela simples razão de que eles não contêm nada de absoluto. Nosso eu possui mesmo uma espécie de unidade, mas não se trata da unidade absoluta, da unidade de uma substância; a unidade absoluta não parece lhe pertencer senão na consciência que ele tem de si e não existe independentemente dessa consciência. Do mesmo modo, nosso eu é permanente de uma certa maneira, mas não é a permanência absoluta de uma substância, a sua existência fora do tempo. A identidade absoluta do eu em diferentes tempos também não é outra coisa senão uma aparência com a qual ele se reveste necessariamente na consciência de si mesmo, mas que não existe independentemente da consciência. Porém, como o nosso eu está organizado de maneira a corresponder a essa aparência de uma unidade absoluta, indivisível e invariável, parece que incorremos em uma contradição lógica negando a ele esse caráter. E é, na realidade, o contrário que acontece: incorremos em contradições lógicas quando atribuímos ao nosso eu um caráter absoluto, quando o consideramos seriamente como uma substância. Essa maneira de ver é absolutamente inconciliável com os fatos. A unidade absoluta exclui antes de mais nada a própria possibilidade de uma vida consciente; porque a consciência implica o desdobramento em um sujeito e um objeto do pensamento. Ela não pode, pela mesma razão, coexistir com a multiplicidade das determinações, das funções internas que fazem a vida de nosso eu. Do mesmo modo, a existência absoluta, a invariabilidade de uma substância, é incompatível com a variabilidade tão manifesta de nosso ser consciente, com o fato de que nós nascemos no tempo e passamos pelas fases tão diferentes da infância, da maturidade e da velhice. Enfim, não se pode tratar de nenhum caráter absoluto do nosso eu a partir do momento em que se pensa no fato de que a nossa vida 
psíquica depende essencialmente das condições e das funções cerebrais. Não existe em nós nada absoluto, exceto a nossa consciência do absoluto. O verdadeiro absurdo, a contradição lógica está, portanto, não na negação, mas na afirmação de uma substância do eu.

Ocorre o mesmo com relação ao mundo exterior.

Parece, à primeira vista, completamente absurdo dizer que os campos e as montanhas, os rios e os oceanos, a própria Terra e os astros existem unicamente na percepção dos sujeitos vivos, e já vimos muitas vezes Berkeley ser "refutado" por alguns gracejos. Mas a que se reduz na realidade esse absurdo aparente? Simplesmente em negar que os fatos da percepção ou da experiência imediata - os únicos fatos verdadeiramente reais e indubitáveis - possam ser explicados pela suposição de objetos exteriores correspondentes às nossas percepções. Bem longe de ser uma afirmação absurda e contraditória, o idealismo não é de maneira alguma uma afirmação, mas uma negação, a negação de um elemento ou de um caráter absoluto em nossa percepção exterior. Mas, os fatos são organizados de maneira a produzir a aparência de um mundo exterior: tudo, em nossa experiência, acontece como se os objetos que nós percebemos fossem, não sensações em nós, mas corpos no espaço. Existe, portanto, um disparate ou um desacordo lógico entre a natureza verdadeira dos fatos e a sua aparência, e esse disparate apresenta, para uma visão superficial, a semelhança de uma contradição lógica. Porém, embora os fatos da experiência exterior sejam incompreensíveis e inexplicáveis, eles não contêm nenhuma contradição lógica, porque eles não contêm nada de absoluto. É, pelo contrário, quando se acredita com firmeza na existência dos corpos, em um caráter absoluto do mundo exterior, que se incorre em contradições lógicas. E é preciso, com efeito, ser bem ingênuo para acreditar que os fatos se expliquem pelo simples fato de que se toma a aparência pela realidade, os corpos que nós percebemos por substâncias verdadeiras; porque é acreditar que os fatos da percepção exterior podem servir a si mesmos de explicação.

Vamos tentar tornar isso mais claro. 
Parece, à primeira vista, que tudo se explica da maneira mais simples e mais natural quando se admite a realidade dos corpos, e essa ilusão ainda é fortalecida pelos progressos da ciência na explicação das coisas. É perfeitamente possível admitir que a explicação dada pela ciência tem um grande valor, que ela tem uma grande utilidade em seu domínio; porém, não é possível se esquecer de que se trata de uma explicação física das coisas, e não de uma explicação metafísica. Ou seja, que ela vale para o domínio da aparência, mas não tem validade absoluta, não tem validade do ponto de vista da realidade verdadeira.

E, primeiramente, precisamos nos lembrar de que o próprio conceito de um corpo, ou seja, de um objeto ocupando um espaço, é logicamente contraditório. Um objeto que ocupa um espaço é um objeto composto de relações, por conseguinte alguma coisa que a análise reduz a zero. Porque as relações supõem objetos reais em relação uns com os outros, e não podem constituir esses próprios objetos. É uma verdade elementar. De resto, a contradição lógica implicada na ideia de corpo já foi exposta tantas vezes, e por filósofos que diferiam tanto de opinião sobre outras questões, que seria supérfluo insistir mais nisso. Na afirmação da natureza contraditória dos corpos, Leibniz e Kant se encontram com du Bois-Reymond e Herbert Spencer.

Mas toda a ação dos corpos à distância ou por contato também implica uma contradição lógica.

Os pensadores do século XVII, Newton entre outros, compreenderam muito bem que a suposição de uma ação a distância é inadmissível. Um corpo não pode agir onde ele não está, porque o espaço que separa os corpos uns dos outros exclui toda ligação íntima entre eles. Para unir ou para colocar em comunicação dois objetos no espaço, é necessário que o espaço que os separa esteja ocupado ou seja transposto. Ora, aquilo que ocupa um espaço é um corpo e aquilo que transpõe um espaço é um movimento; não pode haver, portanto, no espaço, senão corpos e movimentos dos corpos, mas nenhuma força unindo os corpos entre si, e, por conseguinte, nenhuma ação a distância. Em nosso tempo, parece- 
mos ter perdido, na maioria dos casos, o senso dessa dificuldade e aí está um recuo manifesto do pensamento filosófico desde o século XVII. No entanto, a ciência moderna procura eliminar tanto quanto possível, em sua explicação das coisas, a ação a distância e reduzir tudo a movimentos e à transmissão de movimentos por meio do contato.

Porém, admitir a ação por contato — choque ou pressão — é admitir que a própria inércia dos corpos é um princípio de ação, que a própria repugnância em mudar de estado pode produzir mudanças de estado, o que é logicamente contraditório. Como os átomos materiais são separados pelo espaço e, por conseguinte, independentes uns dos outros, se eles fossem substâncias reais, ou seja, se eles existissem realmente, eles não poderiam estar ligados por uma lei comum, mesmo que fosse a lei mecânica da transmissão dos movimentos. Os próprios conceitos de substância e de lei se excluem reciprocamente, um implicando a independência e o outro a dependência mútua das coisas.

Vê-se, portanto, que os dados dos quais as ciências físicas se servem para a explicação física das coisas são eles próprios não somente inexplicáveis, mas também logicamente contraditórios, e não podem, por conseguinte, corresponder a nada de real. Assim, a explicação física não resistiria à prova dos fatos. Ela parece totalmente satisfatória enquanto permanecemos absorvidos na contemplação do mundo exterior e sem aprofundar as coisas. Mas logo surge a questão: como chegaremos ao conhecimento do mundo exterior e de tudo aquilo que se passa nele? $\mathrm{E}$ então a nulidade da explicação física se mostra e não deixa nenhuma dúvida.

Em primeiro lugar, é realmente impossível compreender que alguns movimentos fora de nós possam produzir sensações em nós. Constatamos essa relação de causa e efeito como um fato da experiência, mas esse fato permanece inexplicável. E essa é somente a parte mais fraca da dificuldade. Ainda que fosse totalmente possível compreender que alguns objetos ou acontecimentos exteriores produzem em nós algumas sensações, isso de nada serviria para explicar a nossa própria percepção do mundo exterior. Porque a verdade é que nós percebemos o mundo exterior, os próprios 
corpos imediatamente, tais como eles estão no espaço. Se não pudéssemos perceber os próprios corpos de uma maneira imediata, e particularmente vê-los e tocá-los, não teríamos nenhuma ideia do mundo exterior. Ora, é possível produzir provas experimentais do fato de que os sentidos da visão e do tato só nos fornecem, como todos os nossos sentidos em geral, simples sensações, e que uma percepção imediata do mundo exterior não é possível e não se produz jamais. Chegamos, dessa maneira, a constatar com uma completa certeza que são as nossas próprias sensações que nos surgem como corpos no espaço, e este resultado é confirmado pela análise precedente que estabeleceu bem a natureza contraditória e, portanto, ilusória, dos corpos e de toda ação dos corpos.

Toda a nossa experiência se baseia, portanto, em uma ilusão ou uma aparência, e se essa aparência tem um grande poder sobre o espírito, é porque toda a nossa experiência está organizada de maneira a parecer em conformidade com ela: todos os efeitos percebidos por nós se apresentam como se os objetos que percebemos fossem corpos no espaço; todos os efeitos percebidos parecem proceder dos corpos. Porém, com uma única olhada, vemos que essa organização universal da experiência não pode ser explicada pela hipótese de uma multiplicidade de causas ou de substâncias exteriores; que ela pressupõe, ao contrário, um princípio agente único que abarca todo o sistema da experiência. Portanto, quanto mais a explicação física das coisas parece legítima e natural, menos ela tem verdade e validade do ponto de vista da realidade verdadeira.

Em resumo, eis aqui o que demonstram a constatação e a análise dos fatos e das ideias, e que é muito importante compreender bem: não são os objetos exteriores que nos aparecem em nossas sensações, mas são, pelo contrário, as nossas sensações - da visão, do tato, etc. - que nos aparecem como objetos exteriores, como corpos no espaço. E essa aparência só consegue nos enganar, representar para nós a realidade, e possuir, com efeito, uma verdade relativa, porque ela está sistematicamente organizada de maneira a produzir a mesma ilusão de um mundo material em todos os sujeitos cognoscentes e em todos os tempos, sem 
nenhuma exceção e sem nenhuma falha. Se as alucinações e os sonhos, embora constituídos dos mesmos elementos que as percepções normais, não têm a mesma verdade relativa que essas últimas, é porque eles não têm a sua organização sistemática, porque eles não são comuns a todos os sujeitos cognoscentes. Eles não são partes integrantes do sistema universal da experiência de um mundo material.

\section{Endereço Postal}

Endereço postal: Universidade Estadual do Rio de Janeiro (UERJ). Rua São Francisco Xavier, 524, Maracanã, CEP 20550-013. IFCH - Instituto de Filosofia e Ciências Humanas. $9^{\circ}$ andar. 